\title{
Five Private Language Arguments
}

\section{Abstract}

This paper distinguishes five key interpretations of the argument presented by Wittgenstein in Philosophical Investigations I, §258. I also argue that on none of these five interpretations is the argument cogent. The paper is primarily concerned with the most popular interpretation of the argument: that which that makes it rest upon the principle that one can be said to follow a rule only if there exists a "useable criterion of successful performance" (Pears) or "operational standard of correctness" (Glock) for its correct application. This principle, I suggest, is untrue. The private language argument upon which it rests therefore fails. 


\section{FIVE PRIVATE LANGUAGE ARGUMENTS}

Section §258 of Part I of Wittgenstein’s Philosophical Investigations ${ }^{1}$ (henceforth PI §258) is one of the best-known and most controversial passages of that book. Many philosophers - including Malcolm Budd, John Canfeild, Hans-Johann Glock, P.M.S. Hacker, Paul Johnston, Anthony Kenny, Norman Malcolm, Marie McGinn and David Pears - claim to discern within PI §258 and the surrounding text a powerful argument against the possibility of a necessarily private language. Others dismiss the argument, typically on the grounds that it is verificationist.

My aim in this paper is twofold. The first aim is clarity. The dispute over whether the private language argument of $P I \S 258$ is cogent has been confused by the fact there are now five main interpretations of PI §258 currently on offer, each interpretation presenting a fundamentally different argument. I will set out and distinguish clearly all five private language arguments. My second aim is to explain why none of these arguments is, as it stands, cogent.

I begin by setting out what all the commentators discussed in this paper believe to be the target of PI §258: the suggestion that one might possess a necessarily private language.

\section{Inner Space}

On Wittgenstein's view, the origin of the idea that one might start a private language lies in a highly seductive picture of the mind, a picture Wittgenstein rejects as essentially confused. The picture represents the mind as being akin to the inside of a room, an inner space within which one's sensations, ideas and other mental phenomena are located. Of course, were I to lock myself away inside a physical room it would still be possible in principle for others to find out what's going on inside by, say, peaking through a window, breaking down a door or demolishing a wall. Not so with my inner space. It seems that, while others may experience sensations that are 
qualitatively just like mine, this - the token pain I have right now - remains essentially inaccessible to others.

The picture sketched out above does seem to make fairly straightforward the idea that one might start a necessarily private language. If sensations are phenomena experienced within a necessarily private inner domain, then the introduction of a necessarily private language would appear to be fairly straightforward matter. Suppose a man is imprisoned in a room within which certain objects - rats, let’s suppose - appear and disappear. This prisoner might secretly record those days on which he sees one or more rats by entering a mark in the top right hand corner of the relevant page of his diary - an exclamation mark, let us say. Now there seems, on the face of it, no reason why I should not, in like fashion, record in my diary those days on which a particular sensation makes an appearance within my inner space. Suppose I use "S" in this way, for example. Both codes are "private" in the sense that no one else actually knows them. However, while the former could be taught to someone else, the embroyonic language I use to record my sensations, where sensations are construed as phenomena located within a necessarily private inner space, is necessarily private. Because it is in principle impossible for others to gain entry to my inner domain and establish what I use " $S$ " to record, so it is in principle impossible for others to establish what I mean by "S".

\section{The Importance of the Private Language Argument}

The argument of $P I$ §258 is aimed, not at the suggestion that I might develop a code for the purpose of recording my sensations, a code I just happen to keep private (why should I not develop such a code? $)^{2}$, but rather at the suggestion that the meaning of such a code would be necessarily private, as it would be on the inner space model.

Why is the Private Language Argument important? We find the inner space model of the mind reflected in the work of many philosophers. On Wittgenstein's view, we tend to become 
fixated on this picture as soon as we start to think philosophically about mind and meaning.

Wittgenstein wants to help us free ourselves from its grip on our thinking.

In fact, many philosophers appear to commit themselves, often unwittingly, to the view that each of us already speaks a private language. Locke, for example, argues that the meaning of a word is an "Idea" in the mind of the speaker.

Words in their primary or immediate Signification, stand for nothing, but the Idea in the Mind of him that uses them... ${ }^{3}$

Locke also holds that these Ideas are "hidden from others, nor of themselves can be made to appear" ${ }^{4}$. Consequently, Locke appears to commit himself to the view that each of us speaks a private language: no one else can establish what Ideas I use my words to signify.

Even if we do not suppose, as does Locke, that the function of every word is to stand for some mental item located within one's inner space, it certainly can seem natural to suppose that at least some words - sensation terms like "pain", for example - function in this way. If so, then at least the meaning of one's sensation vocabulary will be necessarily private. Wittgenstein, of course, rejects this account of how our sensation vocabulary functions. On Wittgenstein’s view, the suggestion that "pain" is, or indeed any expression might function as, the name of something necessarily private is deeply confused. The aim of the private language argument of PI §258 is to help alleviate this confusion.

So what is the argument?

\section{PI $§ 258$}

Here is PI §258 in full.

Let us imagine the following case. I want to keep a diary about the recurrence of a certain sensation. To this end I associate it with the sign " $S$ " and write this sign in a calendar for every day on which I have the sensation. - I will remark first of all that a definition of the sign cannot be formulated. - But still I can give myself a kind of ostensive definition.- How? Can I point to the sensation? Not in the 
ordinary sense. But I speak, or write the sign down, and at the same time I concentrate my attention on the sensation - and so, as it were, point to it inwardly.- But what is this ceremony for? For that is all it seems to be! A definition surely serves to establish the meaning of a sign. - Well, that is done precisely by the concentration of my attention; for in this way I impress on myself the connexion between the sign and the sensation. - But "I impress it on myself" can only mean: this process brings it about that I remember the connexion right in future. But in the present case I have no criterion of correctness. One would like to say: whatever is going to seem right to me is right. And that only means that here we can't talk about "rightness".

Precisely what argument is intended here is contentious. I shall refer to the five main interpretations on offer as The Strongly Verificationist No-Independent-Check Argument, The Weakly Verificationist No-Independent-Check Argument, The Circularity Argument, The StageSetting Argument and Kenny's Private Language Argument. On some of these interpretations the private language argument is verificationist; on others it is not. I do not intend to argue for or against any of these interpretations as interpretations. My focus is solely on the supposed cogency of the arguments they attribute to Wittgenstein.

\section{The No-Independent-Check (NIC) Argument}

By far the most popular interpretation of PI §258 construes the text as presenting a version of what I call the No-Independent-Check Argument (henceforth the NIC Argument), which runs, in outline, as follows.

If I introduce " $S$ " as the name of my private sensation and then later want to know whether what I am having is " $S$ " again, I must remember what I previously labelled " $S$ ". But how can I check whether or not I have remembered correctly? I cannot check the accuracy of my memory other than by reference to other memories; but, as Wittgenstein argues at PI §265, that would be no check at all: it would be akin to buying additional copies of the same edition of a newspaper in order to check the accuracy of what is reported.

The situation is very different when a term is defined by reference to a public sample. If, for example, I define " $S$ " by reference to the colour of a piece of cloth, I can physically tape the 
sign "S" to my cloth sample and place it in a drawer for future reference. There now exists something independent to which I can appeal, something against which my memory of what "S" means may be checked. But in the case of the necessarily private sample no such independent check is possible.

So, as Wittgenstein puts it, when it comes to my application of "S", "I have no criterion of correctness": there is nothing independent to which I (or indeed any one else) might appeal to verify that I am applying "S" correctly. ${ }^{5}$

But why should we conclude, as Wittgenstein does, that therefore "whatever is going to seem right is right” and so “we can’t talk about rightness"? So what if I cannot verify whether or not I have remembered correctly? Perhaps I have remembered correctly all the same. There appears to be a lacuna in the argument at this point.

\section{The Strongly Verificationist NIC Argument}

Perhaps the most obvious way of closing this gap in the NIC Argument is to import into it some sort of verification principle. If, for example, we adopt the principle that a statement is meaningful only if it is verifiable, that will allow us to make the move from: that I apply "S" correctly is unverifiable, to: it is meaningless to talk about my having applied " $S$ " correctly. I shall call such versions of the NIC argument Strongly Verificationist.

If the NIC Argument requires that we help ourselves to the Logical Positivists's principle, or something similar, then it is obviously seriously flawed. Verificationism is notoriously counter-intuitive. So the NIC Argument would depend upon a counter-intuitive and as-yetunargued-for premise. The NIC Argument could be salvaged if adoption of the verification principle could be independently justified. But it is, to say the least, contentious whether any such justification can be provided.

In any case, the claim that I cannot verify that I apply "S" correctly is itself dubious. That I apply "S" correctly can perhaps be indirectly verified. For can't I check that my memory is 
generally reliable? I might test the general reliability of my memory by, say, attempting to memorise a sequence of letter/colour pairings printed on a card, writing down what I believe those pairings to be, and then checking whether I have remembered correctly by checking what I have written with what is printed on the card. If I verify that I have remembered correctly in this case, then surely I possess some justification for supposing that I have remembered correctly in the private case too. ${ }^{6}$

Given the very obvious problems with the suggestion that the Private Language Argument relies on a general verificationist premise, most commentators persuaded by the argument have sought to show that no such principle is required. Let us now turn to some of these other interpretations of $P I \S 258$.

\section{The Weakly Verificationist NIC Argument}

Many commentators, while supposing the NIC Argument is what Wittgenstein intends, nevertheless insist that no general verification principle is required. Rather, they suggest that to bridge the gap in the NIC Argument we require only the more modest premise that someone can be said to follow a rule only if there exists "a process of independent verification”, "useable criterion of successful performance"» or "operational standard of correctness" ${ }^{\text {"9 }}$ by which the putative rule-follower's application of the rule can be checked. In short, someone can be said to follow a rule only if it is possible (for the rule-follower, or at least for someone) to verify that he or she does so. I call such versions of the NIC Argument weakly verificationist. This weaker principle also suffices to allow Wittgenstein to make the move from "I have no criterion of correctness” (i.e. there is nothing independent to which I, or indeed anyone else, might appeal in order to verify that I am applying "S" correctly) to "we can’t talk about rightness". 
Colin McGinn ${ }^{10}$, Johnston ${ }^{11}$, Glock, Canfeild ${ }^{12}$ and Pears all interpret PI §258 as offering a weakly verificationist version of the NIC Argument. Johnston, Glock, Canfeild and Pears find the argument compelling (McGinn does not commit himself either way). But should we allow the proponent of the NIC Argument even the weaker principle? I shall argue that we should not. I will examine two versions of the weakly verificationist NIC argument - Glock’s and Pears'-and reveal that they both share the same fundamental flaw.

\section{Glock's Version of the Weakly Verificationist NIC Argument}

Let’s begin by asking how the weaker principle might be justified. I begin with Glock, who offers the following.

[R]ules are standards of correctness ... [T]here is no such thing as a nonoperational standard of correctness, one which cannot even in principle be used to distinguish between correct and incorrect applications. ${ }^{13}$

Glock's thought seems to be this. In order to constitute a genuine standard of correctness a rule must be, as Glock puts it “operational”, i.e. it must be something one can actually consult, something independent against which one's memory of what is correct can be checked. If no such standard of correctness exists, if, in short, it cannot be verified that one applies the rule correctly, then there is no rule.

But this is unpersuasive. It just isn't true that there only exists a rule where there exists an operational standard of correctness. True, we do often set up such objective standards. One way in which we do this is by creating an enduring and independent record of what our rule is. A decorator's colour chart provides an example of such standard, for example. One can check one’s memory of how "puce" should be applied by looking it up on the chart.

Even if no record of a rule is kept, it seems that an operational standard of correctness of sorts might still be provided by a wider community of rule-followers. I can check whether I apply "puce” correctly by asking others. Like the colour chart, they may also provide me with something independent ${ }^{14}$ against which my memory of what "puce" means may be checked. 
However, while rule followers usually do possess an operational standard of correctness, either in the form of an enduring record of what their rule is or in the form of a wider community of rule-followers to whom they might appeal, Glock is surely wrong to suppose that such a standard must be possessed if their activity is properly to qualify as rule-following. Intuitively, it seems clear that a rule can exist even if no operational standard of correctness does.

\section{The Prisoner Case}

To illustrate, let's return to the case of the prisoner introduced towards the beginning of this paper. The prisoner secretly records those days on which he sees one or more rats in his cell by placing an exclamation mark in the top right-hand corner of the relevant page of his diary. Suppose that after a year roughly half the pages in the prisoner's diary have been marked in this way. Intuitively, this prisoner has engaged in a rule-governed practice. Were he now to place an exclamation mark on a page on a day when no rats were seen, he would make a mistake. Yet if, on any particular day, a doubt were to enter into the prisoner's mind - were he to wonder: "Have I been using an exclamation mark to record those days when I have seen a rat or on those days when haven't?" - note that there need not exist anything independent to which he, or indeed anyone else, might appeal in order to check that his memory is correct. Given that the prisoner did not, for example, write in the front of his diary "! = day on which rat is seen” or explain his rule to his jailers, etc., it may be quite impossible for the prisoner or anyone else to verify that his application of "!" is in accordance with either his earlier previous applications or his original intention. Just as in the case of the private linguist, the prisoner's memory of what is correct may now be the only available indicator of correct application. But surely, whether or not the prisoner possesses an “operational” standard of correctness, he may still follow a rule. Glock’s principle would disqualify this prisoner as a rule-follower. It must, therefore, be incorrect. 
What the prisoner case elicits is the very strong intuition that the possibility of verifying that one follows a rule correctly is not a necessary condition of rule-following. It is upon this intuition that all existing versions of the weakly verificationist NIC argument ultimately founder. Unless this weaker verification principle can be independently supported, the weakly verificationist NIC argument fails through reliance on a principle that is both counterintuitive and inadequately justified.

\section{Dealing with a reply}

In reply, it might be suggested that the weakly verificationist version of the NIC argument can easily be reformulated to avoid my objection. A defender of the argument may concede that in order to be a rule-follower one need not actually possess a on operational standard of correctness. Glock's weak verification principle is indeed too strong. However, a still weaker version is viable. What is necessary, to qualify as a rule follower, is that such an operational standard might have existed, i.e. whether or not it actually exists. Notice that this move would allow our prisoner to be a rule-follower after all, while still ruling out the possibility of a necessarily private language. For the prisoner might have written down in the front of his diary "! = day on which a rat is seen”, thereby providing himself with something independent against which his memory of how “!” should be applied might be checked, even though he did not actually do so. Or it might have been the case that our prisoner explained his rule to his jailers to whom he might then have appealed had the prisoner wanted to check how “!” is applied. Either way, he would have possessed an operational standard of correctness. The key difference between the prisoner and the putative private linguist is that while it is not now possible for either of them to check against something independent their memory of what their respective signs mean, the prisoner might have possessed such an independent check. That is why the prisoner follows a rule but the putative private linguist does not. 
The problem with the above reply is that, once it is conceded that there need not actually exist any independent means of verifying the correctness of a rule-follower's memory of how their rule is to be applied, it is gerrymandering of the proponent of the NIC argument nevertheless to insist - just because it allows them to rule out the possibility of a private language - that it must at least be that the case such a check might have existed. In order for such a move to be legitimate the proponent of the NIC argument would need to provide some independent reason to adopt this even weaker principle. However, it is unclear what this independent reason might be. Indeed, those who seek to justify this still weaker principle face an uphill battle, for it too is counterintuitive. For what the prisoner case elicits is the very strong intuition that to be a rule follower all the prisoner need possess is a certain skill or ability: that of applying “!” in accordance with his original intention (something about which I will have more to say shortly). But then why should a private linguist not possess the same sort of ability? That the possibility of verifying that he or she possesses this ability not only does not exist - as in the prisoner case - but could not have existed seems, on the face of it, equally irrelevant.

\section{Pears' Version of the Weakly Verificationist NIC Argument}

Like Glock, Pears also adheres to the principle that one can be said to follow a rule only if it can be verified that one does so - i.e. only if ones applications can be checked against something independent. However, Pears offers a slightly different justification of the principle.

Imagine for example trying to become a good marksman on a rifle-range where you were the only person that ever saw you target and even then you only ever glimpsed it down the sight of you rifle before you fired and never again. In such circumstances there would be no point in pulling the trigger $[\ldots]$ In general someone who can never know what he is in fact doing will not be able to maintain any proficiency at doing it, and will have never been in a position to learn to do it, or even try to do it. An acquired skill, like speaking a language, is not like an automatic performance. Blinking in a bright light is something that you might never know you did, because, not being an intentional action, it stands in no need of a test of success. You might even be born with the capacity to do it and [sic] be given it by neural surgery, but the "gift of tongues", without any test of success available to the speaker, would not count as the gift of language. The point is not that you could not acquire or maintain the skill because it would be 
too difficult to acquire or maintain in such circumstances, but that whatever you did in such circumstances could not count as the exercise of a skill. ${ }^{15}$

Pears concludes that "[l]earning is only possible if there is a standard of success which the pupil can apply to what he does to improve his performance"16; "we cannot even try to acquire a skill without a useable criterion of successful performance" ${ }^{, 17}$. As the putative private linguist possesses no useable criterion of success, nothing he or she does can count as the exercise of a skill.

Is Pears' justification of the weaker principle adequate? Pears claims that one cannot be said to acquire or maintain a skill unless one does so through a process akin to target practice, i.e. through the repeated application of a useable criterion of success. But, again, this is untrue. Let's return once more to the example of the prisoner who decides to record those days on which he sees a rat by writing "!” in the corner of the relevant page of his diary. It seems clear that he immediately comes to possess a skill - that of applying “!” correctly - without his ever bothering to check that he applies "!” correctly. He does not bother introducing a "useable criterion of success” - as he might by, say, writing "! = day on which rat is seen” in the front of his diary for the obvious reason that he knows he does not require such a criterion. He knows his memory is generally reliable. The prisoner acquires his skill, as it were, just like that, without any of the target practice Pears thinks necessary. Nor is it required that he engage in such practice in order to qualify as having maintained this skill.

To this Pears may reply that in the prisoner example I help myself to the prisoner’s existing linguistic skills. The only reason the prisoner can immediately introduce a new sign into his vocabulary and then go on immediately and unerringly to apply it just like that is because the prisoner has already learnt the general skill of introducing and using signs in this way. Pears may insist that at least such a general skill must be acquired and maintained through a process akin to target practice, where a standard of success is applied over and over again in order to improve or 
maintain performance. And it is certainly true that this is a process of the sort the putative private linguist cannot engage in.

The above reply is inadequate, however. Even if we grant Pears that ones general linguistic abilities must at least be acquired and maintained via a process akin to target practice, all that follows is that one cannot start a private language if one does not already possess a public language. But this is not to show that private language is impossible. It is to show, at most, only that one's first language cannot be a private one. Once one has a public language, what is to stop the private linguist introducing " $S$ ” in much the same way as the prisoner introduced "!”, i.e. without any useable criterion of success? As the aim of the private language argument is to show that private languages are impossible, period, Pears version of it therefore fails. ${ }^{18}$

\section{The Fundamental Problem with the Weakly Verificationist NIC Argument}

To take a step back: it is clear that what lies behind Glock’s and Pears' adherence to the weak verificationist principle is the thought that in order to qualify as a genuine rule-follower, as opposed to one whose actions happen merely to coincide with some rule, one must know that one follows that rule. This is plausible. As John Canfeild points out, it seems that more is required for rule following than mere extensional success - "I don’t want just to guess that it is the same; and I don’t want just to be lucky. I want to know it is the same.”"19

But their requirement that in order to know the rule there must exist something independent against which one can check one's application is clearly too strong. Why do we want to say that our prisoner qualifies as a rule-follower - why, indeed, do we want to say about him that he knows what his rule is - despite his not being in possession of any "way of telling" that he applies it correctly? Intuitively, because he possesses an ability: roughly speaking, the ability to apply the sign "!” appropriately in accordance with his original decision. He does not guess blindly how "!" should be applied, and then happen to get lucky. It is because the rule is that "!" should be entered in his diary on just those days on which he sees a rat that he so enters it. 
Obviously, there is a distinction to be made between knowing that $P$ and merely truly believing that $P$. Clearly, there is also a distinction to be made between having an ability and merely guessing correctly how to carry on. In neither case is it enough that one just get lucky. But Glock and Pears claim, in effect, that in order to know that $P$ (at least where $P$ is some claim to the effect the claim that the rule for so-and-so is such-and-such) one must, in addition, possess some method of verifying that $P$. That's what distinguishes someone who knows the rule from someone who merely repeatedly guesses correctly.

But, as I say, this condition is surely too strong: it entails that our prisoner does not know the rule governing “!” when clearly he does. Indeed, the Glock/Pears suggestion as to how to draw the distinction between knowing and merely truly believing (at least when it comes to knowing a rule) prejudges what is highly controversial: that no externalist theory of knowledge, e.g. of the reliabilist or "truth-tracking" variety, can be correct. ${ }^{20}$ In fact, pace Glock and Pears, my intuitions support the view that if the diarist's beliefs about how he should apply "S" are reliable, if they do track the truth, then surely the diarist does knows the rule governing "S".

Granted, much more needs to be said about what does distinguish the rule follower from the lucky guesser (and, indeed, from someone who is merely caused to act in accordance with the rule). What is clear is that the Glock and Pears suggestion as to how we should draw this distinction is unlikely to be correct. As their version of the private language argument rests on acceptance of this suggestion, it too is unlikely to be cogent.

To conclude: it seems that whether or not the diarist can verify how "S" is applied is beside the point. Intuitively, when it comes to rule-following, what is important is that one possesses an ability; it matters not whether one (or indeed anyone else) can verify that one possesses it. While many are convinced by the weakly verificationist NIC Argument, it rests on a highly dubious and inadequately justified principle the counter-intuitive character of which is clearly evinced by the prisoner case. So let us now leave the NIC Argument and look at some other interpretations of $P I \S 258$. 


\section{Hacker's Circularity Argument}

Wittgenstein elsewhere ${ }^{21}$ attacks a certain account of how it is that we are able to apply words correctly. The account involves a sort of internal "looking up" process. Suppose for example, that I am asked to pick a red flower. How am I to know which flower to pick? A natural suggestion is: on hearing the word "red” I conjure up from my memory a mental image or sample. I then compare different flowers with this mental sample until I find a flower that matches. I then pick that flower. Wittgenstein points out that this account is viciously circular. For how did I know which mental image to conjure up? The ability to pick out the red mental sample presupposes precisely the very ability that this inner "looking up" process is supposed to explain - namely, the ability to pick out red things. So the proposed "explanation” of how I am able to pick out red things is really a pseudo-explanation. No real explanatory work has actually been done.

When one is dealing with an objective sample, on the other hand, the situation is quite different. If I want to know which of a number of bathroom tiles is properly described as "puce", I may pull out my decorator's chart, look up "puce”, scan across to the adjacent colour sample and then compare the different tiles with it until I find the right one. My ability to apply "puce" correctly in these circumstances might be properly explained by appealing to a "looking up" process. But when it comes to so-called mental samples the situation is quite different. For of course mental samples are not objectively correlated with the corresponding words. One simply has to remember which sample goes with the word "red". And this requires that one already possess the ability to apply "red" correctly.

P.M.S. Hacker interprets PI §258 as offering a similar argument aimed against the possibility of starting a private language by correlating a word with a mental sample. According to Wittgenstein's interlocutor, I can correlate " $S$ ” with an inner, necessarily private sensation. This sensation then functions as my mental sample of " $S$ ". I can then go on to apply " $S$ " correctly because, when I want to know whether some new sensation is "S" again, I need only conjure up a 
memory of my original mental sample in order to compare it with what I have now. But here is the problem: how do I know which mental sample to conjure up? The proposed explanation of my supposed ability to recognise whether something is " $S$ " actually presupposes that I possess that ability at this point. I need to know what "S" means before I am in a position to conjure up the right sample, for how else am I to know which sample is a sample of " $S$ "? As Hacker puts it,

[d]eliberately calling up the memory sample of $S$ rather than some other sensation requires that one knows what " $S$ " means; yet calling up this sample was meant to be what knowing the meaning of " $S$ " consists in, not to presuppose it. ${ }^{22}$

The interlocutor's account of how I am able to apply " $S$ " correctly is therefore circular: it presupposes what it is supposed to explain. It seems, then, that the ability to apply " $S$ " correctly is something I cannot have.

Hacker’s interpretation is certainly consistent with the text of PI §258. The interlocutor’s explanation of how I come by a "criterion of correctness" fails through being viciously circular.

\section{Refutation of The Circularity Argument}

Hacker's argument is crisply self-contained. It also dispenses with the need to invoke any sort of verificationist premise. The argument does, however, suffer from a serious flaw. Clearly, I can apply the word "red" correctly. Indeed, it seems I can apply it correctly without my having to conjure up any sort of memory sample. But then why can’t I similarly apply “S” correctly without my having to conjure up a mental sample? The Circularity Argument presupposes that it is a necessary condition of my possessing the ability to apply "S" correctly that I engage in some sort of mental looking-up process: in order to know whether this - what I am having now - is S, I must retrieve a memory sample of S in order that I might compare what I have now with it. Certainly, the proposed account of how I am able to apply "S" correctly is circular. But why suppose that I must engage in such a looking up process? Of course Wittgenstein correctly denies that engaging in such a process is a necessary condition of ones possessing the ability to apply "red" correctly. But then why insist that it is a necessary condition of my possessing the ability to apply " $\mathrm{S}$ " 
correctly? However it is that I can apply “red” correctly, why can't I apply "S” correctly in the same way? No reason has been given. So the Circularity Argument, as it stands, also fails.

\section{The Stage-Setting Argument}

Marie McGinn offers an interpretation of PI §258 that also avoids the need to import a verificationist premise into the argument. According to McGinn, $P I \S 258$ is best read as a comment on PI §257, where Wittgenstein points out that

.... great deal of stage-setting in the language is presupposed if the mere act of naming is to make sense.

The point about stage-setting is a familiar one. Wittgenstein famously argues that merely to point to or concentrate ones attention upon an object and say a word does not suffice to lay down a rule for the correct application of that term. If, for example, I point to my red pencil and say "tove”, it is unclear whether my definition is intended to introduce a proper name (eg. of that particular pencil), a common noun or some other sort of expression. Even if we know that "tove" is a common noun, does tove mean red pencil, or pencil, or artifact, or wooden object, or object weighing less than five tons or object currently located in the northern hemisphere of the Earth? Even if we know that "tove” refers to a colour, does it mean scarlet, or red, or red-and-reddyorange, etc? How much of the colour spectrum is "tove” intended to pick out? Introducing an expression by means of an ostensive definition can only work when the grammatical place that that the word is to occupy has already been set out. Such a definition requires, as Wittgenstein puts it, "stage-setting in the language" - the kind of linguistic stage-setting necessary to determine what it is that has been named. We need to be clear that "tove" is intended to name a primary colour, for example. And this in turn requires that we have already mastered the grammar of a colour vocabulary. In the absence of such stage-setting, no rule for the correct application of "tove" is set up. 
On McGinn's reading, the main thrust of PI §258 is that this kind of stage-setting is

absent in the private linguist's case.

The problem here is not that " $S$ " refers to something that is (can be) introspected, but that the private linguist tries to determine what " $S$ " refers to by a bare act of introspection [...], directing attention inwards and saying " $S$ " is not a way of giving a definition. ${ }^{23}$

Hence the definition of " $S$ " in PI §258 is an idle ceremony. No rule for the correct application of

“S” is set up. Malcolm Budd similarly argues about the private linguist’s definition that

his act of private ostensive definition does not give any content to the idea that it would be correct for him to write " $S$ " down on certain subsequence occasions and incorrect for him to write " $S$ " down on certain other occasions. For the combination of an act of attention to a sensation and the utterance of "This is called " $S$ "” does not determine the meaning of " $S$ ": any ostensive definition can be variously understood. It is the way in which a sign is used, or is intended to be used, that determines its meaning, and the concentration of a person's attention upon a sensation as he speaks or writes down the sign implies nothing about how the sign is to be used. ${ }^{24}$

Call this the Stage-Setting Argument.

\section{Refutation of The Stage-Setting Argument}

That the Stage-Setting Argument, at least as set out above, fails the test of cogency may be demonstrated by noting that the same line of reasoning would also rule out the possibility of our starting a public language. For how did public language get started? If the only candidate is by means of an ostensive definition, then, by the same argument, it should be impossible to start a public language. For the linguistic stage-setting required for the very first ostensive definition to succeed would also be absent in the public domain. As we clearly did manage to start a public language, the Stage-Setting Argument cannot be cogent.

The conclusion we ought to draw, of course, is that there must be some other way to start a language. Public language did not start with an ostensive definition. The question then arises: given that public language started not with an ostensive definition, but in some other (presumably less cerebral, more spontaneous and organic) way, why couldn't a private language also get 
started in this other way? If we conceive of the mind as an inner space, a space within which various introspected "somethings" appear and disappear, why should the subject not gradually evolve a practice of using signs to record the occurrence of these "somethings"? 25

In reply it might be claimed that the resources required for this "other way" of starting a language, whatever it is, to succeed are necessarily unavailable within inner space. This claim may even be true. The difficulty, of course, lies in justifying it.

\section{Kenny's Private Language Argument}

Anthony Kenny also offers a non-verificationist interpretation of PI §258. Here is the crux of

Kenny's version of the private language argument.

Suppose next that the private-language speaker says "By " $S$ " I mean the sensation I named "S" in the past." Since he no longer has the past sensation he must rely on memory: he must call up a memory-sample of $S$ and compare it with his current sensation to see if the two are alike. But of course he must call up the right memory. Now is it possible that the wrong memory might come at this call? If not then " $S$ " means whatever memory occurs to him in connection with " $S$ ", and again whatever seems right is right. If so, then he does not really know what " $S$ " means. It is no use his saying "Well, at least I believe that this is sensation $S$ again", for he cannot even believe that without knowing what "S" means. ${ }^{26}$

Note that a key assumption made here is that if it is possible that the speaker might call up the wrong memory-sample of $S$, then "he does not really know what "S" means". But this assumption is surely false. Again, compare the case of the prisoner. Is it possible that he might misremember what "!” means? Of course. Does that entail that he does not really know what "!” means? Of course not. For it is unlikely that he will misremember: his memory is fairly reliable. As a reliable, though of course not infallible, user of "!" the prisoner surely can be said to know what " $S$ " means. But then why shouldn't the private linguist also be a reliable user of " $S$ "? No reason is has been given.

Bizarrely, Kenny’s argument seems to require that any rule-follower be infallible about how his or her rule should be applied: if it is even possible that one might misremember how a 
sign should be applied, then one does not know what it means. This is clearly too strong a requirement. So perhaps I have misunderstood. Perhaps by “possible” Kenny means something weaker. For example, perhaps he just means not unlikely. Then Kenny's argument would no longer require rule followers be infallible. But on this interpretation Kenny's argument still fails. For then his argument would rest upon the principle that if it is not unlikely (or whatever) that the wrong memory sample may be called up, then whatever seems right is right. This principle is patently false.

\section{Conclusion}

The first and most obvious conclusion I wish to draw is that, far from presenting an unambiguous argument, PI §258 is highly cryptic. There are five very different interpretations of the argument on offer. Whatever the virtues of PI §258, clarity is not among them. Second, on none of these five interpretations is the argument, as it stands, cogent.

But what if, rather than offering a single argument, PI §258 and the surrounding text is actually intended to offer a raft of arguments? What if, in reply, it's suggested that there is no "private language argument” as such but rather a series of interlocking arguments and observations which taken together suffice to show that the suggestion that one might start a necessarily private language is nonsensical. The piecemeal approach I have taken to refuting the arguments is therefore unfair. The arguments and considerations discussed here should be approached en masse. What might seem to be a series of flawed arguments may then reveal themselves to interlock in a mutually supportive way. Together they form a watertight whole.

The problem with this suggestion is that it simply isn't true. Taken together, the five arguments discussed here resemble not a watertight container but a leaky sieve. They do not remedy each other's faults.

Because each of the five arguments fails for a different reason, the temptation for a defender of "the private language argument" presented with a refutation of one version may be to 
slide over to another, perhaps without acknowledging or even realising that any such slide has taken place. Those unpersuaded by “the private language argument” may thus discover that when they start to pursue their doubts the Wittgensteinian leads them into a labyrinth of arguments within which the pursuer quickly becomes lost, thereby allowing their prey an easy escape. This may be one of the reasons why defenders of "the private language argument" can be such elusive quarry, and why disputes over the cogency of the "private language argument” typically end in stalemate with neither side admitting defeat. My aim in this paper has, in effect, been to provide a map or overview of this Wittgensteinian labyrinth. Most importantly, I have also shown that, as it stands, none of the labyrinth's corridors leads us to the conclusion Wittgenstein wishes to reach.

\footnotetext{
${ }^{1}$ Ludwig Wittgenstein, Philosophical Investigations, Oxford, Blackwell, 1953.

${ }^{2}$ Whether Wittgenstein also insists that any language must actually be shared, as opposed to just shareable in principle, is an issue I set to one side. See section entitled “A Second Objection” below.

${ }^{3}$ An Essay Concerning Human Understanding, Oxford, Clarendon Press, 1975 (III.ii.2).

${ }^{4}$ Ibid.

${ }^{5}$ For a fairly straightforward example of the NIC Argument, see of Norman Malcolm, "Exposition and Criticism of Wittgenstein's Investigations” in O.R. Jones (ed) The Private Language Argument, Macmillan, 1971, London, pp33-49.

${ }^{6}$ This point is also made by Pears in his Wittgenstein, London, Fontana, 1971, p161.

${ }^{7}$ Paul Johnston, Wittgenstein: Rethinking the Inner, London, Routledge, 1993, p21.

${ }^{8}$ David Pears, The False Prison, Vol 2, Oxford, Clarendon Press, 1988, p345.

${ }^{9}$ Hans-Johann Glock, A Wittgenstein Dictionary, Oxford, Blackwell, 1996, p312.

${ }^{10}$ Wittgenstein on Meaning, Oxford, Blackwell, 1984, p48.

${ }^{11}$ Johnston maintains that "where we can properly speak of rule-following, there are established ways of determining whether or not something is in accordance with the rule”, Johnston, ibid, p20. Rule following requires that there be established a "process of independent verification." ibid, p21.

12 David V. Canfeild, "Private Language: Philosophical Investigations section 258 and Environs” in Robert L Arrington and Hans-Johann Glock (eds) Wittgenstein’s Philosophical Investigations, London, Routledge, 1992.

${ }^{13}$ Glock, ibid, p312.

${ }^{14}$ Independent of my memory, at least, though of course the check is not independent of anyone's memory.

${ }^{15}$ Pears, ibid, p333.

${ }^{16}$ Pears, ibid, p344.

${ }^{17}$ Pears, ibid, p345.

${ }^{18}$ This is not to say that the conclusion that one cannot have a private language without possessing a public one would not be an important and worthwhile conclusion to draw, of course.

${ }^{19}$ Canfeild, ibid, p131.

${ }^{20}$ The expression "truth-tracking” comes from Nozick, Philosophical Explanations, Oxford, Clarendon, 1981, chpt 3.

${ }^{21}$ See, for example: Ludwig Wittgenstein, The Blue and Brown Books, London, Blackwell, 1972, p3.

${ }^{22}$ Appearance and Reality, Oxford, Blackwell, 1987 p109 [note that I have inserted "S” for "pain"].

${ }^{23}$ Marie McGinn, Wittgenstein and the Philosophical Investigations, London, Routledge, 1997, p131.
} 
${ }^{24}$ Wittgenstein's Philosophy of Psychology, London, Routledge, 1989, pp59-60.

${ }^{25}$ One might be tempted to reply that Wittgenstein elsewhere rules out the possibility of an individual evolving such a rule-governed practice in isolation. If one supposes, along with Kripke, that Wittgenstein embraces the "sceptical solution" to the rule-following paradox, then one will suppose that on Wittgenstein's view any rule-governed practice must actually be shared. Therefore it is impossible for the private linguist to evolve such a practice in the manner I have just suggested. The difficulty with this reply is, first, that this Kripkean interpretation is highly controversial. Secondly, the argument of PI §258 is presumably not supposed to depend on adoption of the "sceptical solution", for then it would in any case be rendered redundant: if any rule-governed practice must be shared, it follows immediately, without the need for any further argument, that a necessarily private language is impossible. Thirdly, in any case McGinn cannot make this reply for she denies Wittgenstein adopts the "sceptical solution".

${ }^{26}$ Wittgenstein, Penguin, Harmondsworth (England), 1973, p194 